\title{
NEOLOGIA I GRAMÀTICA: ENTRE EL NEOLOGISME LÈXIC I EL NEOLOGISME SINTÀCTIC
}

\section{NEOLOGY AND GRAMMAR: BETWEEN LEXICAL NEOLOGISM AND SYNTACTIC NEOLOGISM}

\author{
JORDI GINEBRA \\ Universitat Rovira i Virgili \\ jordi.ginebra@urv.cat
}

Resum: En aquest treball es mira de contribuir a objectivar el concepte de neologia sintàctica, de manera que pugui ser un recurs classificatori operatiu. La proposta és utilitzar l'expressió neologisme sintàctic per referir-nos als canvis de règim verbal que no són concomitants amb canvis semàntics (ja que llavors haurem de parlar de neologisme semàntic), i que tampoc concorren amb altres procediments neològics. En aquest sentit, un neologisme sintàctic no és un neologisme lèxic, una paraula nova, com sí que ho són els neologismes semàntics. Quan diem que el neologisme sintàctic exclou el canvi semàntic, però, no ens referim al significat relacionat amb les propietats estructurals de tipus temàtic i aspectual que determinen les diverses alternances sintàctiques regulars dels verbs i que els agrupen en classes sintàctiques. Així, l'aparició de l'alternant causatiu transitiu en un verb inacusatiu que no tenia aquest alternant il.lustra un cas de neologia sintàctica. La neologia sintàctica, doncs, reclassifica verbs, però no crea verbs nous. A més, pot fer adquirir a un verb una alternança que el col-loca fora de les classes establertes. Llavors ens acostem a l'àmbit del canvi sintàctic.

Paraules clau: neologia, lexicologia, semàntica, canvi sintàctic, alternança verbal.

Abstract: This work is an attempt to clarify the concept of syntactic neology with the aim of finding a working taxonomic device. My proposal is to use the label syntactic neologism to refer to those changes in verbal government that are not linked to semantic change (which would qualify as semantic neologism), nor to other word formation procedures. Thus, a syntactic neologism is not a lexical neologism, a new word, as indeed is the case with semantic neologism. Nevertheless, when we say that syntactic neologism excludes semantic changes, we do not refer to the meaning related to the structural properties (thematic roles and aspect) that determine regular syntactic alternations in verb classes. Therefore, if a new transitive causative variant is formed upon an unnacusative verb (which previously did not have that use) the result would be a case of syntactic neology. So syntactic neology reclassifies verbs, but does not create new verbs. In addition to 
that, syntactic neology can provide the verb with a new variant that places the verb outside established syntactic classes. In this case we would be approaching the sphere of syntactical change.

Key words: neology, lexical morphology, semantics, syntactic change, verb alternations.

\section{$\cos \cos$}

\section{INTRODUCCIÓ}

El concepte de neologia pertany a la lexicologia (o, si es vol, a la morfologia lèxica). Parlem de neologismes per referir-nos a les paraules noves, a les unitats lèxiques de nova creació. No parlem normalment de neologisme quan ens referim a un fenomen gramatical o sintàctic nou. No diem que l'aparició de la passiva pronominal en català va constituir un neologisme sintàctic, sinó que diem que va constituir una innovació (o, simplement, un canvi). Tanmateix, la separació entre gramàtica i lèxic, com se sap, no és sempre facil d'establir i, per tant, la vinculació de la gramàtica amb la neologia (lèxica) és una qüestió que caldria atendre i estudiar acuradament. Entre altres coses perquè encara no sabem fins a quin punt determinats canvis gramaticals en la història de les llengües han estat promoguts o afavorits per canvis previs en unitats lèxiques concretes; per l'aparició de neologismes amb determinades propietats específiques, en definitiva.

De fet, la relació entre sintaxi i neologia és encara més estreta del que acabem de suggerir, perquè una unitat lèxica no és sols un feix de trets fonològics, morfològics i semàntics, sinó que es caracteritza també per les seves propietats sintàctiques. Hi ha propietats sintàctiques de les llengües que són independents del lèxic (o, si més no, que es poden estudiar i descriure fent abstracció del lèxic: tal idioma no té pronoms relatius, tal altre idioma no té cas morfològic, tal altre presenta un ordre oracional fix), però n’hi ha que no són sinó la projecció de propietats lèxiques (o, si es vol, el resultat de generalitzar i abstreure a partir de l'anàlisi de trets lèxics específics de naturalesa sintàctica). I, en la mesura que aquestes propietats sintàctiques caracteritzen paraules concretes (tal verb és transitiu, tal verb no admet la passiva, tal nom admet un complement genitiu objectiu, etc.) i, sobretot, en la mesura que les paraules concretes poden perdre alguna d'aquestes propietats sintàctiques i en poden adquirir de noves, és evident que som en un espai que està relacionat amb la neologia (una altra qüestió és si el fet que un mot adquireixi un tret gramatical nou implica necessàriament, o no, que puguem dir que hem detectat un neologisme lèxic). 
És clar que la possibilitat d'afirmar que un mot ha adquirit una propietat sintàctica nova (per exemple, que un verb intransitiu s'ha convertit en un verb transitiu) depèn no sols del resultat de l'observació empírica, sinó també en bona part del marc teòric en què ens movem. En un marc teòric que estableixi, per exemple, que característiques com la telicitat, la causativitat o la classe semàntica dels arguments dels verbs depenen exclusivament de la configuració sintàctica — com ara, en l'esfera de la gramàtica generativa, en els models neoconstructivistes o en models projeccionistes «tous»—, les unitats verbals apareixeran al lèxic amb molt poques especificacions. El contrast entre "ser un verb tèlic» $\mathrm{i}$ "ser un verb no tèlic", per exemple, estaria associat a l'estructura sintàctica, i no pas a una especificació de l'entrada lèxica del verb. Igualment, un argument $\mathrm{X}$ s'interpretarà semànticament com a tema en virtut de la posició estructural que ocupi, i no caldrà, doncs, un nivell de representació lèxica en el qual aquest argument aparegui especificat com a tal. En aquest marc, detectar empíricament que un verb tradicionalment intransitiu es comença a usar com a transitiu no tindria interès des del punt de vista de la teoria del lèxic, perquè el canvi no seria en realitat cap canvi rellevant, ja que respondria simplement a una realització ja prevista per la sintaxi.

En el treball de neologia — que és una àrea de la lingüística vinculada estretament amb la descripció de llengües concretes, amb la documentació, amb l'avaluació de les dades empíriques, amb el desenvolupament històric dels idiomes i, en certa manera, amb la lingüística aplicada - sembla més adequat moure's en un marc de plantejaments lexicalistes (dits també projeccionistes). Amb això no es vol dir que aquest marc teòric sigui superior a l'altre. Des d'un punt de vista general probablement són complementaris, i cada un és més adequat en funció de l'objectiu específic de la recerca. ${ }^{1}$

I. Aquest és el motiu que va dur Lorente a adoptar un plantejamenyt lexicalista "fort», el de la gramàtica lexicofuncional de Bresnan i Kaplan, en la seva tesi doctoral (Lorente 1994), atès el propòsit eminentment lexicogràfic de la seva recerca (vegeu també Lorente 1996). En un panorama general de les dues principals línies teòriques actuals sobre la relació entre lèxic i sintaxi (projeccionistes i neoconstructivistes), Mendikoetxea (2008) afirma que els models projeccionistes (lexicalistes) presumiblement són més capaços de descriure la riquesa dels fenòmens que apareixen en les llengües naturals, mentre que els models neoconstructivistes segurament tenen més força explicativa. En rigor, en els models constructivistes purs fins i tot el terme mateix de polisèmia no té gaire sentit. Els verbs, llavors, no tenen significats múltiples. Hi ha molts verbs que designen conceptes compatibles amb més d'una construcció sintàctica, i són aquests els verbs que poden aparèixer en diverses construccions sintàctiques amb sentits que varien de l'una a l'altra (Mendikoetxea 2008). 


\section{EL PROBLEMA DE LA NEOLOGIA GRAMATICAL}

Aquest treball vol ser una petita contribució a l'estudi de la relació entre la neologia lèxica i el canvi de trets sintàctics dels mots, és a dir, una contribució a la caracterització dels neologismes "gramaticals», entesos com les unitats lèxiques que adquireixen noves propietats sintàctiques. És important de destacar que no identifiquem neologisme gramatical amb paraula nova; precisament aquest és, en tot cas, un dels objectius de la recerca: mirar de determinar formalment en quins casos hem de considerar que el canvi de propietats sintàctiques en un mot genera una nova unitat lèxica i en quins casos no. Dit d'una altra manera: mirar de determinar la diferència entre neologisme semàntic i neologisme sintàctic, i de determinar, en definitiva, si és que val la pena conservar per als estudis de neologia aquesta darrera categoria. L'interès — i la dificultat- de l'estudi de la neologia gramatical ja van ser detectats per l'Observatori de Neologia de l'Institut Universitari de Lingüística Aplicada de la Universitat Pompeu Fabra, que tant en la guia metodològica (Observatori 2004a: 19) com en la base de dades en línia BOBNEO va preveure la possibilitat de recollir unitats de la classe neologisme sintàctic, que va definir com el neologisme "que implica un canvi de subcategoria gramatical», però que va caracteritzar amb una certa ambigüitat. ${ }^{2}$ Una altra mostra de la dificultat de tractar amb els neologismes gramaticals o sintàctics es pot obtenir del fet que en els treballs col-lectius sistemàtics d'explotació i anàlisi de les dades del BOBNEO promoguts per l'IULA (per exemple, Observatori $2004 \mathrm{~b}$ o Cabré, Domènech \& Estopà 20I4) aquest procediment neològic no ha estat mai tractat. ${ }^{3}$

Aquesta dificultat, doncs, justifica que el nostre treball no vulgui sinó ser, com s'ha dit, una petita contribució. I és també una de les raons que expliquen que adoptem un enfocament elemental, bàsicament taxonòmic. L'altra raó és que la taxonomia — que durant unes quantes dècades ha estat menyspreada pels lingüistes pel seu escàs valor explicatiu - torna a ser important avui, almenys en projectes de recerca col.lectius en què es manipulen electrònicament grans quantitats de dades i en els quals participen grups d'investigadors de formació de vegades diversa i desigual. La imprecisió —o la explicitació insuficient — en els criteris de classificació pot conduir a

2. Així, si d'una banda indica que el canvi de règim verbal és un exemple de canvi de subcategoria gramatical, de l'altra afegeix que no cal recollir els «neologismes de tipus sintàctic que fan referència a règims verbals» perquèl'objectiu del projecte és detectar la neologia lèxica. El BOBNEO conté actualment (maig de 20I4) prop de 700 fitxes de neologismes sintàctics, que corresponen sobretot a casos de canvi de la categoria de gènere, de canvi de règim verbal i de canvi de "pronominalitat» verbal, alguns lligats a canvis semàntics i d'altres no.

3. Fins ara en aquestes ratlles hem usat indistintament els designadors neologia gramatical i neologia sintàctica, però a partir d'ara farem servir només aquest darrer. 
petits errors o a interpretacions excessivament particulars en el tractament del material; errors i interpretacions que, tanmateix, per causa dels procediments automatitzats o semiautomatitzats de recuperació de la informació, és possible que invisibilitzin dades rellevants. Volem contribuir, doncs, a fer una primera proposta pràctica relativa a les etiquetes taxonòmiques que ens poden servir, en l'esfera de la neologia sintàctica, per a l'explotació i anàlisi de corpus i bases de dades de la llengua catalana. (De fet, parlar de "primera proposta» és agosarat, perquè, com acabem de veure, l'Obneo ja ha fet passes en aquesta línia.)

Restringirem, però, l'abast de les nostres indagacions a la categoria verbal i, més en concret, a l'àmbit del règim verbal (i qüestions connexes com l'estructura temàtica i argumental i l'estructura aspectual dels verbs). Partim de la idea que el canvi de règim d'un verb - la neologia rectiva - és un fenomen que s'emmarca en l'àmbit de la neologia sintàctica: un verb que «adquireix» un règim verbal que no tenia —un verb que es recategoritza rectivament - és un verb que adquireix una propietat sintàctica nova. Però també de la idea que la recategorització rectiva és, a més, un fenomen transversal en l'àmbit de la formació de mots i de la neologia: hi ha prefixació i sufixació amb recategorització rectiva, conversió amb recategorització rectiva, neologia semàntica amb recategorització rectiva, etc. (Lògicament, també hi prefixació, sufixació, conversió, etc., sense recategorització rectiva; llavors parlem d'herència rectiva. La recategorització rectiva es pot dividir en increment rectiu - $\mathrm{el}$ derivat té més complements que la base—, reducció rectiva —el derivat té menys complements que la base— $\mathrm{i}$, potser, reordenació rectiva — per a d'altres fenòmens. $)^{4}$

En rigor, probablement la neologia rectiva, quan no va lligada a d'altres processos neològics —afixació, neologia semàntica, etc.—, podria considerar-se una classe específica de conversió, en la mesura que el que caracteritza el procediment neològic que anomenem conversió és que hi ha canvi de trets gramaticals sense que hi hagi modificació formal de la base lèxica: un verb que canvia de règim canvia de trets gramaticals — de subcategoria gramatical—, però no canvia de forma. L'única operació que caldria fer en la definició de conversió perquè la neologia rectiva hi capigués és canviar la formulació "canvi de categoria gramatical sense modificació de la base lèxica» per la formulació "canvi de categoria o subcategoria gramatical sense modificació de la base lèxica». D'aquesta manera no sols la neologia rectiva seria una

4. Sobre la qüestió de les propietats d'alguns afixos relatives a la conservació o recategorització de l'estructura argumental i rectiva de les bases - un tema que aquí no serà tractat - pot consultar-se, per al català, Bernal (2000), Cabré (1994 i 2002), Ginebra (201I), Ginebra \& Rull (2010), Gràcia (1995), Gràcia et alii (2000), Lorente \& Cabré (1999), Observatori (2004b) i Rull (1999 i 2004). 
classe de conversió, sinó que també ho seria, per exemple, el canvi de gènere inherent en els substantius. De fet, Cabré (2006) ja apunta en aquesta línia i, en realitat, no és infreqüent trobar en estudis de neologia — sobretot de neologia terminològica— que la neologia sintàctica i la conversió s'identifiquen. ${ }^{5}$

\section{LES ALTERNANCES VERBALS COM A ÀMBIT DE LA NEOLOGIA SINTÀCTICA}

Utilitzarem en aquesta exposició, si no indiquem expressament una altra cosa, dades procedents del BOBNEO, bàsicament del català. Inclourem també, però, dades de la llengua castellana. Intentarem delimitar el concepte de neologia sintàctica, almenys per contrast amb la neologia semàntica. Defensarem que la neologia sintàctica és canvi rectiu sense canvi semàntic, però exclourem del «canvi semàntic» certes alternances «previsibles» de significat. ${ }^{6}$

Una de les fitxes neològiques del BOBNEO conté aquesta oració, en la qual el verb bombardejar — que, contra el que pot semblar, no està usat en sentit figuratapareix classificat com a neologisme sintàctic pel fet que no porta complement directe, ja que, segons les obres lexicogràfiques de referència, el verb bombardejar és transitiu:

A continuació, uns consells publicitaris, i després seguirem bombardejant.

Tanmateix, molt pocs lingüistes defensarien avui —si és que n'hi ha cap-que l'ocurrència del verb que recull la fitxa i l'ocurrència del verb d'una frase com Van bombardejar les línies enemigues corresponen a unitats lèxiques diferents. Tot i així, l'autor de la fitxa no pot ser criticat, en la mesura que va aplicar adequadament un criteri explícit i clar.

5. El problema és una mica més complex, però. En la mesura que en aquest treball es vol distingir precisament entre neologia semàntica (amb canvi de règim) i neologia sintàctica (canvi de règim sense canvi semàntic), és clar que la neologia sintàctica tampoc no pot vincular-se a la conversió amb canvi semàntic. En realitat aquest punt es relaciona amb el problema de la frontera entre conversió i neologia semàntica, un problema que, com se sap, és encara tema de debat.

6. No cal dir que, per descomptat, també pertany a la neologia sintàctica el polimorfisme, és a dir, la simple modificació gramatical merament formal, sense cap conseqüència en l'esfera del significat. Aquest és un punt que no tractarem, però, entre altres raons perquè constitueix una qüestió oberta, ja que, com se sap, hi ha força autors d'orientació generativista o cognitivista que neguen precisament que hi pugui haver canvi sintàctic deslligat del canvi semàntic. D'acord amb aquests autors, qualsevol canvi sintàctic s'ha de poder justificar en termes semàntics (una tesi en relació amb la qual ara ens abstenim de mostrar la nostra posició). 
El problema té una doble vessant. D'una banda, si seguim el criteri lexicogràfic perdeterminar la neologicitat d'un element —el criteri lexicogràfic considera neologisme qualsevol paraula que no apareix en un corpus lexicogràfic d'exclusió-, ens trobem, en relació amb la qüestió que ens ocupa, una informació molt pobra. En el cas de la neologia sintàctica caldria considerar neologisme qualsevol paraula que tingui un tret de subcategoria gramatical que no apareix al corpus lexicogràfic de referència. Però la informació sobre subcategorització gramatical que ofereixen els corpus lexicogràfics usuals de referència és, com se sap, pobra, imprecisa i ambigua. Per tant, si es vol seguir el criteri lexicogràfic —una posició que trobem correcta-, caldria disposar d'una obra de referència que descrivís amb precisió totes les propietats sintàctiques de cada verb (règim categorial, restriccions semàntiques de selecció, papers temàtics que assigna, estructura aspectual, etc.), per poder establir després, davant d'un nou ús del verb, si presenta o no propietats no previstes a la seva entrada lèxica. Deixo per a un altre moment el debat sobre el marc teòric que hauria de servir de guia per a la redacció d'aquestes entrades lèxiques (que, en qualsevol cas, com hem dit, hauria de ser un marc lexicalista fort, amb entrades altament especificades). Sigui com sigui, hi ha obres en altres idiomes, elaborades seguint plantejaments teòrics diversos, que poden servir de referència, com el Dictionnaire explicatif et combinatoire du français contemporain de Mel'čuk i col-laboradors (1984-1999), el diccionari d'alternances verbals de Levin (1993) o el treball de Vázquez, Fernández i Martí (2000). En català disposem del diccionari prototipus que conté la tesi doctoral de Lorente (1994) i, específicament per al règim verbal, del Diccionari d'us dels verbs catalans (Ginebra \& Montserrat 1999). ${ }^{7}$

La segona vessant del problema és que aquestes entrades lèxiques de referència, a més, no han de servir exclusivament per determinar en quin cas l'ocurrència no és sinó la materialització d'una propietat sintàctica prevista i en quin cas hi ha neologia rectiva, sinó que, a més a més, han de servir per determinar si la neologia rectiva, quan n'hi ha, correspon al canvi de subcategoria gramatical d'un verb sense que hi hagi unitat lèxica nova, i en quin cas la neologia rectiva crea una paraula nova (o és senyal de creació d'una paraula nova), és a dir, en quins casos hi ha neologia semàntica. I això depèn directament del que ara anomenem alternances verbals. Tornant al cas anterior del parell bombardejar / bombardejar + CD (un dels contrastos que estan relativament ben estudiats), avui hi ha acord general que no hem de considerar-les unitats lèxiques diferents, sinó alternants d'un mateix verb, és a dir, dues maneres de realitzar-se

7. Tornarem més endavant sobre el diccionari de Lorente (1994). La qüestió, però, seria superar els 55I verbs que descriu l'autora i poder arribar a una xifra que s'acostés als Io.00o. 
—de "presentar-se»— una mateixa unitat lèxica. Llavors diem que el verb bombardejar regeix un complement directe i té alternança intransitiva $-\mathrm{O}$ absoluta-, i presenta, doncs, dos alternants, el transitiu i l'intransitiu. En canvi, un verb com utilitzar, que exigeix sempre la presència del complement directe, no téalternança intransitiva. Aquesta característica, lògicament, ha d'estar especificada en l'entrada lèxica de cada verb. ${ }^{8}$

Un escenari semblant es presenta davant d'una altra de les fitxes del BOBNEO, que recull l'oració següent:

La inflació subjacent, especialment en el seu component de béns industrials, seguirà desaccelerant-se els pròxims mesos.

També ara la fitxa segueix correctament el protocol establert. El verb desaccelerar és transitiu i no pronominal en les obres de referència, $i$ en aquesta ocurrència apareix com a intransitiu i pronominal. Però també ara la majoria de lingüistes explicarien que l'ocurrència de la fitxa no correspon a una unitat lèxica nova, sinó a l'alternant ergatiu d'un verb causatiu. També ara, però, el verb desaccelerar hauria d'estar especificat a l'entrada lèxica com a verb que presenta l'alternança ergativa.

La descripció de les unitats verbals en les entrades lèxiques que han de servir com a corpus de referència ha d'incloure, doncs, totes les alternances de cada verb, perquè només així és possible establir que una determinada ocurrència verbal correspon a la realització d'una d'aquestes alternances previstes. Entre aquestes alternances hi hauria, a més de l'alternança transitiva i l'alternança causativa/ergativa, d'altres com l'alternança passiva o l'alternança reflexiva, circumstància que, en el treball de classificació, impediria etiquetar com a neològiques construccions que no són sinó la realització de propietats presents en l'entrada lèxica del verb. Una qüestió addicional — potser, almenys en part, de caràcter més notacional que no teòric- és definir si cada entrada hauria d'especificar explícitament cada una de les alternances del verb concret o si alguna d'aquestes alternances no caldria que hi constessin perquè ja es deriven de propietats més generals assignables a les diferents classes de verbs. Sigui com sigui, el que és rellevant de cara al treball concret en neologia empírica és poder determinar si l'ocurrència del verb que trobem en una determinada frase correspon o no a realitzacions previstes en la descripció del verb, tant si aquesta descripció és exhaustiva per a

8. Sobre l'alternança intransitiva pot consultar-se, en català, Lorente (I994: I9I-I93) o Rosselló (2002: I898-1904) i, en un marc més general, per exemple, Levin \& Rappaport Hovav (2005: 99). Com se sap, la presència o absència del complement es relaciona bàsicament amb un canvi aspectual: l'eliminació de l'objecte converteix una realització en una activitat, per tal com l'objecte «mesura» l'acció del verb i la fa tèlica, mentre que l'absència de l'objecte força una interpretació atèlica de l'eventualitat. 
cada unitat lèxica — i, per tant, en part redundant—, com si es deriva de l'adscripció del verb a una determinada classe sintàctica. ${ }^{9}$

La situació és diferent si l'ocurrència correspon a una realització no prevista en l'entrada lèxica del verb, com sembla que seria el cas del verb aflorar en aquesta oració en castellà:

bien para mantener los recursos como dinero negro, bien para aflorarlos a través de declaraciones complementarias del impuesto sobre la renta.

La base és aflorar 'surgir, aparecer, asomarse a la superficie', un verb inacusatiu de canvi d'estat de causa interna (amb un únic argument, que semànticament és tema), com s'il.lustra en una frase com aquesta:

Las sonrisas y los abrazos colmaron los noticieros, el dinero afloró más allá de lo que estaba previsto.

En la primera oració anterior el verb s'ha causativitzat [aflorarlos = hacerlos aflorar], és a dir, ha adquirit un argument amb valor semàntic de causa que no tenia la base, un argument que es realitza com a subjecte i que provoca que es mogui el subjecte del verb "primitiu» a la posició de complement directe del derivat.

La causativització és un fenomen de neologia rectiva, perquè un verb adquireix propietats sintàctiques que no tenia. ${ }^{10}$ ¿Podem parlar, ara sí, de neologia lèxica? ¿Podem dir que hi ha un verb aflorar nou, que s'afegeix al lèxic al costat del primer aflorar? Naturalment, la resposta dependrà dels plantejaments teòrics, però la nostra proposta és que no. Sembla raonable sostenir que quan els canvis corresponen exclusivament als trets que utilitzem per fer generalitzacions sobre les classes sintàctiques de verbs, el canvi és gramatical: es passa d'un verb d'una classe a un verb d'una altra classe.

9. Lorente (20I0), per exemple, descriu els trets sintàctics i semàntics que fan possible que un verb admeti la construcció reflexiva, i per tant seria possible no incloure la propietat «admet la construcció reflexiva» en les entrades lèxiques dels verbs que satisfacin els trets pertinents. Tanmateix, en el seu diccionari prototipus la mateixa Lorente (1994) marca per a cada entrada si el verb és sensible a la regla lèxica de reflexivització. És evident que l'establiment de classes de verbs és un objectiu de més entitat descriptiva i explicativa, però la «lexicografització» de les propietats d'aquestes classes de verbs segurament és més útil en treballs de recerca empírics. En qualsevol cas, com veurem, la idea de les classes sintàctiques de verbs no es pot reduir del tot a un recurs notacional, ja que resultarà rellevant precisament per caracteritzar la neologia sintàctica.

IO. El terme causativització és en part problemàtic per la seva polisèmia. No ens referim ara a causativització com a equivalent a la realització causativa ja prevista en l'entrada lèxica d'un verb (com a materialització d'una alternança), ni tampoc a la possibilitat d'admetre la realització com a perífrasi causativa, que és el significat amb què usa el terme Lorente en la seva tesi doctoral (I994). 
En aquest cas, d'un verb inacusatiu a un verb causatiu/ergatiu. Canvien les propietats sintàctiques del verb, però no s'ha generat una unitat lèxica nova. Tanmateix, la neologia rectiva d'aquesta naturalesa ha de formar part del treball neològic, perquè la migració de verbs d'una classe a una altra classe és un fenomen que sembla altament interessant tant per a la descripció lingüística com per a la teoria sintàctica.

Les propietats sintàctiques de les diferents classes de verbs poden descriure's en termes d'alternances — cada classe sintàctica presenta unes determinades alternances— $\mathrm{i}$, llavors, els diferents canvis de propietats sintàctiques dels verbs —els diferents tipus de neologia rectiva- poden classificar-se seguint aquestes alternances prèviament definides, de manera que noms com intransitivització i causativització serviran per definir els diferents subtipus de recategorització rectiva. La recategorització rectiva dels verbs lligada exclusivament a l'adquisició, la pèrdua o la reorganització d'alternants (amb el manteniment, però, del significat idiosincràtic del verb) formarà part de la neologia sintàctica, però no de la neologia lèxica. Aquesta proposta sembla operativa, perquè la recerca sobre alternances verbals és avui intensa en el marc de les teories projeccionistes, i per tant hi ha molts estudis que poden servir de guiatge. En el cas català, en concret, es podria partir de les regles lèxiques descrites i exemplificades en la tesi de Lorente (1994), que, tot i que no estan pensades ni formulades com a denominacions de subprocessos de neologia sintàctica, ofereixen uns motllos formals que resultarien força adaptables a la descripció dels fenòmens a què ens referim. ${ }^{11}$

Probablement un altre fenomen clar de canvi de règim que podria ser tractat com a neologisme sintàctic en aquest marc de les alternances és el que representa l'ocurrència de preocupar en aquesta frase (també procedent del BOBNEO):

Resulta gratificant saber que al president Zaplana li preocupa la llengua dels valencians i que manifesta la seua voluntat de superar conflictes estèrils...

Com se sap -i no ens podem allargar en relació amb una qüestió que ha suscitat una bibliografia extensa-, els verbs psicològics de la classe B (com ara preocupar $\mathrm{d}$ 'acord amb el seu règim tradicional) lliguen un argument experimentador que fa de complement directe i un argument estímul que fa de subjecte, mentre que els verbs psicològics de la classe $\mathrm{C}$ (com ara agradar) lliguen un argument experimentador

II. Quan parlem de classes sintàctiques de verbs o de propietats gramaticals dels verbs no som més precisos perquè no volem prejutjar quin és el marc teòric concret en el qual caldria establir les alternances. Però ens sembla que el treball descriptiu de què tractem encaixaria en més d'un marc. Per exemple, en el marc de les teories de la descomposió lèxica — com les que es basen en els treballs de Levin \& Rappaport Hovav- segurament les classes sintàctiques podrien identificar-se amb els diferents patrons d'estructura eventiva. 
que fa de complement indirecte i un argument estímul que fa de subjecte (Rosselló 2002: I92I-I922). Durant el segle XX es va produir un canvi rectiu parcial, ja que uns quants verbs de la classe $\mathrm{B}$ van passar a funcionar en català també com a verbs de la classe C. La qüestió, en relació amb el tema que ens ocupa, és determinar si la unitat lèxica que subjau a les frases Li preocupa la llengua dels valencians (construcció nova) i El preocupa la llengua dels valencians (construcció tradicional) és la mateixa o no. Si en el pas d'una construcció a l'altra hi ha neologia lèxica o, contràriament, adquisició d'un nou alternant verbal. Pot semblar raonable i acordat amb la intuïció acceptar que el significat lèxic és el mateix en totes dues oracions, i que el que canvia és el significat configuracional i que, per tant, en el pas històric d'un alternant a l'altre no hi ha neologia lèxica (encara), però sí canvi de propietats sintàctiques. De fet, durant molts anys els professors de gramàtica havíem considerat que el contrast entre, per exemple, li molesta i el molesta era merament formal, però des de l'aparició de l'estudi de Cabré \& Mateu (1998) sabem que aquest canvi té a veure també amb la modificació estructural de propietats aspectuals i tematicoargumentals del verb. Es tracta, doncs, de l'aparició d'un nou alternant: d'un cas, doncs, de neologia sintàctica. ${ }^{12}$

Els verbs psicològics de la classe $\mathrm{B}$ que adquireixen l'alternant datiu tenen especial interès perquè il.lustren un fenomen que també caldrà tenir en compte a l'hora de caracteritzar la neologia sintàctica. Fixem-nos que fins ara hem donat per descomptat que les classes sintàctiques de verbs s'associen a feixos d'alternances prèviament definits. Ser un verb de la classe sintàctica $n$ vol dir tenir el nombre i tipus d'alternances que defineixen la classe $n$. Però en el cas d'aquests verbs el que s'esdevé, en realitat, és que apareix una nova classe sintàctica, perquè fins ara no hi havia verbs amb aquestes propietats. Per tant, la neologia sintàctica ens informa que un verb d'una classe passa a ser també d'una altra classe (totes dues prèviament definides), i a més ens informa si, amb l'adquisició d'alternances que no col-loquen el verb en cap dels esquemes establerts, de fet es creen noves classes sintàctiques — nous feixos d'alternances (i això ja és més interessant per a la caracterització sintàctica general d'una llengua).

Naturalment, en relació amb aquest punt hi ha casos que seran més o menys problemàtics, almenys a primer cop d'ull. Fixem-nos en aquestes altres dues fitxes del BOBNEO:

I2. Tanmateix, la qüestió de la frontera entre significat verbal i significat de la construcció (el que correspondria a un alternant de la mateixa unitat lèxica) per als verbs psicològics que presenten aquesta alternança acusatiu/datiu no és del tot clara, almenys d'acord amb les anàlisis de Royo (20I4: 137). Per a la qüestió, vegeu també Royo (20II). 
La llet xinesa traficada és perseguida a Barcelona.

El tema s'ha polemitzat massa.

Les ocurrències dels verbs polemitzar i traficar que hi apareixen corresponen a l'alternança passiva (morfològica en un cas, pronominal en l'altre). Però els verbs polemitzar i traficar són verbs de règim preposicional, és a dir, verbs que no satisfan les condicions que permeten la construcció passiva (la més elemental, la de ser verbs transitius). Aquí la qüestió —en part metodològica - és determinar si aquestes ocurrències mostren que, contra el que sembla que s'ha esdevingut fins ara en la història del català, els verbs preposicionals catalans —alguns verbs preposicionals catalans - també admeten la passiva (o també han començat a admetre la passiva i, per tant, han adquirit una alternança que no tenien), o si la construcció passiva el que mostra és que prèviament (amb una anterioritat lògica, no necessàriament documental) aquests verbs preposicionals s'han convertit en transitius (traficar llet, polemitzar un tema). La decisió del lingüista és, com diem, en part metodològica. Si acceptem com a postulat que un verb que no sigui transitiu no admet mai l'alternant passiu, llavors cal descriure el canvi establint que s'ha format un verb transitiu, del qual la passiva en seria un signe (que polemitzar i traficar s'han transitivitzat). Si no acceptem aquest postulat, llavors podem dir que aquests verbs preposicionals han adquirit l'alternant passiu. Per tant, en un supòsit no s'ha creat una classe sintàctica nova, i en l'altre sí (verbs preposicionals amb alternança passiva). Sigui com sigui, el que sembla més rellevant en relació amb el que ens ocupa i, en general, de cara a la documentació de la neologia sintàctica és treballar amb una de les dues opcions — la que es determini finalment — obertament formulada i acceptada.

\section{NEOLOGIA RECTIVA (RECATEGORITZACIÓ SINTÀCTICA) I NEO- LOGIA SEMÀNTICA}

¿En quins casos cal parlar de neologia lèxica, de paraula nova, associada a un canvi rectiu? Com hem dit, ens sembla que quan el canvi que permeti parlar pròpiament de neologisme semàntic. Atès que abans hem il.lustrat en primera instància el fenomen de les alternances verbals amb la intransitivització, també ara ens servirà un fenomen relacionat amb la intransitivització per tractar aquest punt.

Com se sap, en castellà, a partir del verb blanquear 'fer tornar blanc' es va formar, per neologia semàntica, el verb blanquear _'ajustar a la legalitat fiscal (el diner 
procedent de negocis delictius o injustificables)'. El verb derivat va heretar l'estructura argumental i el règim del primitiu: blanquear té un argument intern que es realitza com a complement directe i blanquear també. Amb el verb blanquear, que ha tingut una gran difusió (¿per què deu ser?), s'hi ha operat un nou procés. El BOBNEO documenta, així, que, per expressar el predicat blanquear dinero, avui n'hi ha prou amb dir blanquear, que ha adquirit el sentit, doncs, de 'blanquear dinero':

Este vertiginoso incremento es negro, ya que procede del tráfico de estupefacientes por persona interpuesta, pero muy pronto entrará en la máquina de blanquear.

Fixem-nos que aquest blanquear, 'blanquear dinero' ha incorporat a la seva entrada lèxica el significat idiosincràtic de 'dinero', però no pas cap tret de tipus temàtic o aspectual dels que serveixen per establir les classes sintàctiques de verbs. Sembla que ara sí que podem parlar de neologia lèxica, de paraula nova. Ara: també és cert que el neologisme semàntic blanquear ${ }_{3}$ 'blanquear dinero' ha perdut un argument, el complement directe. Hi ha hagut, doncs, intransitivització.

En els estudis sobre herència argumental es parla d'absorció quan un prefix realitza un argument de la base. Llavors l'argument ja no es realitza sintàcticament en el derivat (Gràcia et alii 2000: 23). Així, el sufix -dor, que forma noms, absorbeix l'argument extern del verb primitiu (Gràcia 1995: 23, 44). Quan no hi ha intervenció d'un afix al qual pugui atribuir-se l'absorció de l'argument que ja no apareix al derivat, parlar d'absorció es fa una mica més complicat. En l'esfera del règim verbal, però, quan es forma un verb absolut a partir d'un verb transitiu sense la intervenció d'afixos, podríem parlar d'absorció si el derivat perd formalment el complement directe del primitiu i esdevé intransitiu, però realitza "semànticament» l'argument eliminat (l'incorpora de manera inherent a la matriu semàntica com a participant de l'eventualitat denotada). Dit altrament, podríem parlar d'absorció quan el verb derivat té el mateix significat que la seqüència de $\mathrm{V}+\mathrm{CD}$ que li ha fet de base. És per això que proposem la denominació absorció rectiva per descriure el pas de blanquear, 'ajustar a la legalitat fiscal (el diner procedent de negocis delictius o injustificables)' a blanquear ${ }_{3}$ 'blanquear dinero'. Des del punt de vista formal l'absorció rectiva és una intransitivització, però es distingeix de la intransitivització de l'alternança intransitiva en el fet que amb l'absorció rectiva hi ha neologia lèxica, verb nou, mentre que amb la intransitivització només hi ha realització d'un alternant de la mateixa unitat lèxica, és a dir, neologia sintàctica. En català es pot il.lustrar d'una manera que em sembla clara aquest contrast amb el verb beure tal com apareix en les oracions següents (material de l'autor): 
T'anirà molt bé beure aigua i sucs.

Aquí està prohibit menjar, beure i fumar.

El seu problema és que beu.

La diferència entre la primera frase i la segona és que en la primera hi ha l'alternant transitiu del verb beure 'ingerir líquid', mentre que en la segona hi ha l'alternant intransitiu (o absolut) del mateix verb 'ingerir líquid'. En canvi, en la tercera frase hi ha un verb nou format per absorció rectiva, el verb beure 'beure vi. ${ }^{13}$

Un altre cas de neologia lèxica — de neologia semàntica — lligada a la intransitivització dels verbs és el que podríem anomenar bloqueig del complement directe. La teoria morfològica parla de bloqueig quan el derivat perd un argument en relació amb el primitiu, però no l'absorbeix (Gràcia et alii 2000: 23). Així, els adjectius en -ble hereten el complement directe del verb primitiu (i el reordenen com a subjecte), però perden l'argument que en el primitiu fa de subjecte (Gràcia 1995: 99). En l'àmbit rectiu podríem parlar de bloqueig del complement directe quan un verb transitiu canvia de significat i perd l'objecte, però sense que en la matriu semàntica del nou verb hi hagi rastre de l'argument que feia de complement directe del primitiu. Per exemple, en castellà el verb cantar (com passa amb el corresponent verb català) pot portar complement directe. Fa uns anys es va formar a partir d'aquest verb, primer com a propi de l'argot juvenil, un neologisme semàntic (no enregistrat al BOBNEO, per tal com ja el recull el DRAE) que significa 'fer molta pudor' (que il.lustra una frase com Le cantan los pies). El nou verb és intransitiu, i està format a partir d'un verb transitiu, però no n'ha absorbit el complement directe. La relació rectiva entre cantar $_{1}$ i cantar ${ }_{2}$ és, doncs, de bloqueig.

Discriminar entre els casos d'absorció de CD o bloqueig de CD pot no resultar senzill a primer cop d'ull. Aquestes dades, però, em sembla que poden ser útils per entendre bé el bloqueig (utilitzem de nou material del BOBNEO). El verb arrasar

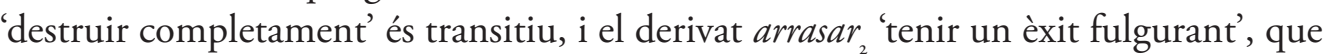
il.lustrem tot seguit, és absolut:

Acompanyant la que més que previsiblement serà una de les pel-lícules que arrasaran en taquilla, aquest disc es fonamenta sobretot en els importants noms del rap i el hip-hop.

I3. Es podria pensar que en el pas de la frase T'anirà molt bé beure aigua i sucs a la frase Aquí està prohibit menjar, beure i fumar també hi ha d'alguna manera absorció, i que per tant la distinció que establim no és tan clara. Fixem-nos, però, que en aquest canvi hi ha, en tot cas, absorció d'un paper temàtic, mentre que en el pas de beure vi a beure 'beure vi' hi ha, en termes de descomposició lèxica, l'absorció d'una constant (o, si més no, un procés de lexicalització que modifica la constant del verb). 
La relació d'arrasar amb el primitiu arrasar és de bloqueig del CD, ja que el significat del nou verb no equival al conjunt $\mathrm{V}+\mathrm{CD}$ del primitiu. El verb col.locar 'fer que (una cosa) estigui (en un lloc)' és transitiu, i el derivat col.locar 'provocar un estat d'embriaguesa emocional', que també il.lustrem tot seguit, és absolut:

Veure ballar Canales, hi ha moments que col-loca. Deu ser el duende, una mena d'orgasme que tot flamenc duu dins, i que el colpeja fins migpartir-lo.

La relació de col.locar amb el primitiu col.locar és de bloqueig del CD, ja que el significat del nou verb no equival al conjunt $\mathrm{V}+\mathrm{CD}$ del primitiu. El verb entendre és transitiu, i el derivat entendre 'ser homosexual', que també il.lustrem tot seguit, és absolut:

Igual que tampoc és gaire comprensible que porti un negoci gai un home que no entengui.

La relació d'entendre ${ }_{2}$ amb el primitiu entendre és de bloqueig del CD, ja que el significat del nou verb no equival al conjunt V + CD del primitiu. El verb installar és transitiu, i el derivat instal.lar 'fer una exposició'?, que també il.lustrem tot seguit, és absolut:

Josep Ginestar, un dels artistes que enguany ha instal-lat aXàbia, que tambéés el seu poble.

La relació d'instal.lar amb el primitiu instal.lar és de bloqueig del CD, ja que el significat del nou verb no equival al conjunt $\mathrm{V}+\mathrm{CD}$ del primitiu. El verb privar és transitiu, i el derivat privar ' 'beure (alcohol)', que tambéil.lustrem tot seguit, és absolut:

En Marc no fuma fum, no priva, no surt amb dones, amb homes ni amb híbrids.

La relació de privar amb el primitiu privar és de bloqueig del CD, ja que el significat del nou verb no equival al conjunt $\mathrm{V}+\mathrm{CD}$ del primitiu.

D’altres casos no són tan clars. ¿Quina és la relació rectiva del neologisme verbal d'aquesta frase amb la base?

Si mirem la Història, veurem que els grans artistes ho són perquè van trencar.

La base podria ser trencar motlles o una expressió semblant, i llavors seria un cas d'absorció — així es va classificar aquest cas a Ginebra \& Llagostera (20I0)—, però 
potser es podria argumentar que trencar, en aquesta frase, vol dir 'ser innovador', i llavors el rastre sintàctic de la base quedaria diluït. Igualment, a Ginebra \& Llagostera (20IO) es va tractar com a cas de bloqueig el de la frase següent:

Tenia una nova parella i no estava essent clara la situació, no sabia si seguir o tallar, no n'estava satisfeta.

S'havia partit de la idea que la base era tallar amb la parella i, per tant, es va considerar que el nou verb, absolut, havia bloquejat el complement preposicional. Però ara sembla que, en tot cas, caldria parlar d'absorció del CP (sempre pressuposant que tallar derivi de tallar amb la parella — que constituiria un primer neologisme-, i no directament del sentit bàsic i general de tallar).

Hem il-lustrat la recategorització rectiva lligada a la neologia semàntica (neologia lèxica) amb dues classes d'intrasitivització: l'absorció i el bloqueig. De fet la tipologia és prou més rica, i només exemplificarem amb un tipus més, que és el que mostren les ocurrències del verb beure que apareixen en aquestes fitxes:

Peter Mayle s'ha fet famós a tot el món amb els seus llibres sobre la Provença, uns dels quals són novel.les i els altres cròniques vistes que beuen de la tradició dels llibres de viatges.

Els seus quadres de gran format ens presenten una mirada irònica i crítica del món amb un llenguatge gràfic que beu del pop-art per fer-se absolutament actual.

El director italo-americà demostra d'on beu el seu cinema, autocitant-se constantment en aquest poema èpic brutal sobre la fundació traumàtica de Nova York.

El debut homònim d'aquest trio australià beu de la distingida tradició del rock romàntic.

De l'estètica urbanofuturista del film de Luc Besson, que al seu torn bevia sense satisfer-se de Metrópolis i Blade runner.

Cal recordar que de COM Ràdio en beuen més de I50 emissores locals.

El que caracteritza aquestes ocurrències és que el verb beure s'hi ha recategoritzat semànticament (hi té un sentit figurat, d'acord amb l'expressió tradicional). Però també que en totes apareix obligatòriament (perquè sigui possible la nova interpretació) un complement preposicional introduït per de que no era obligatori per a la interpretació tradicional del verb beure 'ingerir líquid'. El neologisme, doncs, està lligat a la incorporació del nou argument: el verb s'ha recategoritzat rectivament. 
Hi ha neologia rectiva vinculada a la neologia semàntica: hi ha neologia lèxica, però no hi ha neologia sintàctica. ${ }^{14}$

\section{COMENTARI BREU SOBRE ETIQUETES TERMINOLÒGIQUES}

Les etiquetes utilitzades en aquesta exposició no volen ser propostes formals. El terme intransitivització és polisèmic. Designa la realització d'un alternant intransitiu d'una entrada lèxica que ho prevegi (i encara, en aquest marc, pot fer referència a alternances de mena diversa), també designa (en els marcs teòrics que ho preveuen) l'elisió del complement directe en una frase ja generada —un fenomen sintàctic i no pas lèxic_ i i, com hem vist, expressa tant la incorporació a una base lèxica d'un alternant intransitiu (neologia sintàctica) com l'absorció i el bloqueig del complement directe (neologia semàntica). Un comentari anàleg pot fer-se de causativització (i de transitivització). Alhora, s'ha usat bloqueig del complement directe, i no solament bloqueig, perquè també hi pot haver casos de bloqueig del complement indirecte, del complement preposicional i del complement predicatiu regit. Potser s'hauria pogut parlar d'intrasitivització per bloqueig. Tambél'absorció pot afectar, a més del complement directe, els altres complements argumentals (intransitivització per absorció hauria pogut ser una alternativa). En tot cas, sí que seria convenient arribar a acords terminològics, ja que, com hem dit, la univocitat terminològica, sempre desitjable, sembla ara, en el context de recerques col-lectives en què es processen digitalment grans quantitats de dades, especialment important.

\section{CONCLUSIONS}

La neologia és un fenomen lèxic, però en les llengües els fenòmens lèxics i els fenòmens sintàctics es relacionen, i aquests lligams són encara poc coneguts. Sembla que determinats canvis gramaticals en la història dels idiomes han estat promoguts o afavorits per l'aparició de neologismes amb propietats sintàctiques específiques, i avui la possibilitat de compilar extenses bases de dades lingüístiques i de processar-les

I4. D'aquest fenomen se n'ha dit incorporació de CP a Ginebra \& Llagostera (20I0). Si tenim en compte que el sintagma que faria d'adjunt en la construcció amb la base ha passat a complement argumental en el derivat, també en podríem dir, seguint un suggeriment terminològic de Denis Creissels (2006), promoció d'adjunt a argument (o, simplement, promoció d'adjunt). 
amb rapidesa i eficàcia permet plantejar-se recerques interessants en aquesta línia (en el rastreig dels "antecedents lèxics» de fenòmens gramaticals generals) que eren impensables fa encara no gaires anys. Però aquesta possibilitat només fructificarà si el material compilat està categoritzat i etiquetat de manera "sintàcticament orientada», un objectiu que no és facil, entre altres raons per la complexitat mateixa dels fenòmens que caldria estudiar i per la complexitat de les teories sintàctiques que ens haurien de proporcionar les eines d'anàlisi.

En concret, en aquest treball s'ha mirat de contribuir a precisar i objectivar — de manera que pugui ser un recurs classificatori operatiu-el concepte de neologiasintàctica, introduït en els estudis neològics catalans per l'Observatori de Neologia de l'Institut Universitari de Lingüística Aplicada de la UPF. El material de treball específic han estat sobretot les dades de règim verbal — de neologia rectiva — recollides al BOBNEO.

La proposta, de fet en sintonia amb el protocol de recollida de dades del BOBNEO mateix, és utilitzar l'expressió neologisme sintàctic per referir-nos als canvis de règim de les unitats verbals que no són concomitants amb canvis semàntics, ja que en aquest darrer supòsit hem de parlar, senzillament (i d'acord amb la terminologia comunament admesa), de neologisme semàntic (que pot ocorrer, doncs, amb canvi de règim — recategorització rectiva - i sense canvi de règim — herència). De fet, la neologia rectiva és transversal en l'àmbit de la formació de mots, i és només el neologisme rectiu que no es pot vincular amb cap altre procediment neològic el que hauria de rebre el nom de neologisme sintàctic. En aquest sentit, un neologisme sintàctic no és un neologisme lèxic, una paraula nova, com sí que ho són els neologismes semàntics, els neologismes formats per conversió, els neologismes formats per prefixació, etc. (La taula I presenta un esquema de la relació entre neologia rectiva i alguns procediments neològics.) No és un neologisme lèxic, però s'hi relaciona molt estretament, i per tant resulta recomanable no deixar-lo de banda en els estudis neològics.

Taula I. La recategorització rectiva en la neologia (semàntica, sintàctica i conversió)

\begin{tabular}{|l|l|l|}
\hline \multirow{2}{*}{ Conversió } & \multirow{2}{*}{ 1. amb canvi semàntic } & a) amb canvi de règim (recategorització rectiva) \\
\cline { 3 - 3 } & & b) sense canvi de règim (herència rectiva) \\
\cline { 3 - 3 } & \multirow{2}{*}{ 2. sense canvi semàntic } & a) amb canvi de règim (recategorització rectiva) \\
\cline { 3 - 3 } & & b) sense canvi de règim (herència rectiva) \\
\hline Neologia semàntica & \multirow{2}{*}{ 1. amb canvi semàntic } & a) amb canvi de règim (recategorització rectiva) \\
\cline { 3 - 3 } & & b) sense canvi de règim (herència rectiva) \\
\hline Neologia sintàctica & 2. sense canvi semàntic & a) amb canvi de règim (recategorització rectiva) \\
\hline
\end{tabular}


Quan diem que el neologisme sintàctic exclou el canvi semàntic, però, no ens referim al significat relacionat amb les propietats estructurals — de tipus temàtic $\mathrm{i}$ aspectual— que determinen les diverses alternances sintàctiques regulars dels verbs i que els agrupen en classes sintàctiques. Així, l'aparició de l'alternant causatiu transitiu en un verb que no tenia aquest alternant (per exemple, en un verb inacusatiu o en un verb ergatiu inherent) il.lustra un cas de neologia sintàctica (però no pas de neologia lèxica). La neologia sintàctica, doncs, reclassifica verbs, però no crea (de moment) verbs nous: fa passar un verb de la classe sintàctica $a$ (amb unes alternances definides) a la classe sintàctica $b$ (amb unes altres alternances, també definides).

La neologia sintàctica també opera fent adquirir a un verb una alternança que no el col-loca en cap de les classes establertes. Llavors som en el camí de creació de noves classes sintàctiques (de nous feixos d'alternances). I llavors potser ens allunyem encara més de la neologia lèxica (com dèiem, no parlem de neologisme quan ens referim a un fenomen gramatical o sintàctic nou), però ens acostem a l'interesantíssim món de la innovació sintàctica.

JoRdi Ginebra

Universitat Rovira $i$ Virgili

jordi.ginebra@urv.cat

\section{REFERÈNCIES BIBLIOGRÀFIQUES}

BernaL, Elisenda (2000) «Els sufixos verbalitzadors del català. Relacions semàntiques i diccionari», tesi doctoral, Barcelona, Institut Interuniversitari de Lingüística Aplicada, Universitat Pompeu Fabra.

BoBNeO = Plataforma OBNEO. Institut de Lingüística Aplicada de la Universitat Pompeu Fabra. [<http://obneo.iula.upf.edu/pobneo $>$, data de consulta: primer semestre de 20I4.]

Cabré Castellví, M. Teresa (1994) A l'entorn de la paraula (II). Lexicologia catalana, València, Servei de Publicacions de la Universitat de València.

- (2002) "La derivació», dins Joan Solà, Maria-Rosa Lloret, Joan Mascaró \&

Manuel Pérez Saldanya (dirs.), Gramàtica del català contemporani, vol. I, Barcelona, Empúries, pp. 73I-775.

- (2006) "La clasificación de los neologismos: una tarea compleja», Alfa. Revista de Lingüistica, 2, vol. 50, pp. 229-250. 
Cabré Castellví, Teresa, Ona Domènech Bagaria \& Rosa Estopà Bagot, eds. (20I4) Mots nous en català / New words in Catalan. Una panoràmica geolectal / A diatopic view, Amsterdam, John Benjamins.

Cabré Monné, Teresa \& Jaume Mateu Fontanals (1998) «Estructura gramatical i normativa lingüística: a propòsit dels verbs psicològics en català», Quaderns. Revista de Traducció, 2, pp. 65-8I.

Creissels, Denis (2006) Syntaxe générale une introduction typologique, vol. iI, París, Hermes.

Ginebra, Jordi (20II) «Un cas de neologia lèxica i sintàctica: els verbs formats amb el prefix auto-», dins Maria-Rosa Lloret \& Clàudia Pons (eds.), Noves aproximacions a la fonologia i la morfologia del català, Alacant, Institut Interuniversitari de Filologia Valenciana, pp. 217-242.

Ginebra, Jordi \& Roser Llagostera (2OIO) «Tendències en el règim sintàctic dels neologismes verbals: anàlisi contrastiva català-castellà», dins Imma Creus, Maite Puig \& Joan R. Veny (eds.), Actes del Quinzè Col-loqui Internacional de Llengua i Literatura Catalanes. Universitat de Lleida, 7-II de setembre de 2009, vol. I, Barcelona, Publicacions de l'Abadia de Montserrat, pp. 46I-474.

Ginebra, Jordi \& Anna Montserrat (I999) Diccionari d'ús dels verbs catalans, amb la col-laboració de Xavier Rull \& Anna Saperas, Barcelona, Edicions 62.

Ginebra, Jordi \& Xavier Rull (20I0) «Tendències en el règim sintàctic dels neologismes verbals: una aproximació", dins M. Teresa Cabré, Ona Domènech, Rosa Estopà, Judit Freixa \& Mercè Lorente (eds.), Actes del I Congrés Internacional de Neologia de les Llengües Romàniques, Barcelona, Institut Universitari de Lingüística Aplicada, pp. 377-390.

Gràcia, Lluïsa (1995) Morfologia lèxica. L'herència de l'estructura argumental, València, Servei de Publicacions de la Universitat de València.

GrÀCIA, Lluïsa et alii (2000) Configuración morfológica y estructura argumental: léxico y diccionario, [Vitòria], Servicio Editorial de la Universidad del País Vasco.

Levin, Beth (1993) English verb classes and alternations, a preliminary investigation, Chicago, University of Chicago Press.

Levin, Beth \& Malka Rappaport Hovav (2005) Argument Realization, Nova York, Cambridge University Press.

Lorente, Mercè (1994) Aspectes de Lexicografia: representació i interpretació gramaticals, tesi doctoral, Universitat de Barcelona. [Edició en CD-ROM: Barcelona, Institut Universitari de Lingüística Aplicada de la Universitat Pompeu Fabra, 2002.] 
— (1996) «La teoria de l'estructura argumental i la representació del lèxic», dins Axel Schönberger \& Tilbert Dídac Stegmann (eds.), Actes del Desè Col.loqui Internacional de Llengua i Literatura Catalanes. Frankfurt am Main, I8-25 de setembre de 1994, vol. III, Barcelona, Publicacions de l'Abadia de Montserrat, pp. 323-335. - (20I0) «Verbs pronominals de font lèxica: reflexivitat i reciprocitat inherents», dins Imma Creus, Maite Puig \& Joan R. Veny (eds.), Actes del Quinzè Col.loqui Internacional de Llengua i Literatura Catalanes. Universitat de Lleida, 7-II de setembre de 2009, vol. I, Barcelona, Publicacions de l'Abadia de Montserrat, pp. 435-445. Lorente, Mercè \& M. Teresa CABRÉ (1999) «L'estructura argumental dels predicats derivats», Estudi General, I7-18, pp. 67-78.

MeL'ČUK, Igor A. et alii (1984-1999) Dictionnaire explicatif et combinatoire du français contemporain. Recherches lexico-sémantiques, Mont-real, Les Presses de l'Université de Montreál, 4 vol.

Mendikoetxea, Amaya (2008) «En busca de los primitivos léxicos y su realización sintáctica: del léxico a la sintaxis y viceversa», dins Teresa Cabré Monné (ed.), Lingüistica teòrica: anàlisi i perspectives II, Bellaterra, Servei de Publicacions de la UAB / Institut Interuniversitari de Filologia Valenciana, pp. 55-102.

Observatori de Neologia (2004a) Metodologia del treball en neologia: criteris, materials i processos, Barcelona, Institut de Lingüística Aplicada de la Universitat Pompeu Fabra.

- (2004b) Llengua catalana i neologia, Barcelona, Meteora.

Rosselló, Joana (2002) «El SV I: Verbs i arguments verbals», dins Joan Solà, MariaRosa Lloret, Joan Mascaró i Manuel Pérez Saldanya (dirs.), Gramàtica del català contemporani, Barcelona, Empúries, vol. II, pp. I853-1949.

Royo, Carles (20II) «Aspectes sintàctics i semàntics dels verbs psicològics: estructura argumental i estructura eventiva», treball de recerca inèdit, Universitat Autònoma de Barcelona.

- (20I4) «Alternança acusatiu/datiu i flexibilitat semàntica dels verbs psicològics catalans», treball inèdit, Universitat Autònoma de Barcelona / Universitat de Barcelona.

Rull, Xavier (1999) «-Eig: entre la genuïnitat i el calc», Els Marges, 63, pp. 59-88.

- (2004) La formació de mots. Qüestions de normativa, Vic, Eumo Editorial.

VÁzquez, Glòria, Ana Fernández \& M. Antònia Martí (2000) Clasificación verbal. Alternancias de diátesis, Lleida, Edicions de la Universitat de Lleida. 